\title{
INTERVENSI UNTUK MENGURANGI STIGMA PADA PENDERITA SKIZOFRENIA
}

\author{
Ardiyani ID*, Muljohardjono $\mathrm{H}^{* *}$ \\ * Dokter Umum, Peserta PPDS I Prodi Psikiatri Departemen/SMF Ilmu Kedokteran Jiwa FK UNAIR/RSUD dr. Soetomo Surabaya \\ **Guru Besar,Psikiater Konsultan, Staf Pengajar Departemen/SMF Ilmu Kedokteran Jiwa FK UNAIR/RSUD dr. Soetomo Surabaya
}

\begin{abstract}
ABSTRAK
Skizofrenia merupakan suatu gangguan jiwa dengan manifestasi kondisi psikotik yang berat dan persisten serta bersifat kronis dimana sebagian besar penderita skizofrenia tidak mendapat penatalaksanaan secara tepat karena kuatnya stigma di masyarakat, juga akibat dampak stigma pada skizofrenia yang menghambat pemulihan, hubungan interpersonal, penurunan harga diri, kemampuan bersosialisasi, dan menimbulkan kualitas hidup yang buruk. Terdapat beberapa jenis strategi intervensi sebagai upaya mengurangi stigma yang dapat diterapkan dan disesuaikan dengan kondisi di Indonesia dengan mempertimbangkan permasalahan dan hambatan serta tantangan yang menyertainya dengan target yang berbeda dan tujuan yang diharapkan.
\end{abstract}

Kata kunci : Skizofrenia, stigma, intervensi untuk mengurangi stigma 


\section{A. PENDAhuluAN}

Adanya stigma membentuk sebuah ciri negatif pada diri seseorang yang disebabkan oleh pemikiran orang lain. Hal ini mengakibatkan pola pemikiran, perilaku, dan tindakan yang berbeda dari berbagai pihak baik dari keluarga, teman, pemerintah, penyedia layanan kesehatan dan lapangan pekerjaan, bahkan oleh diri mereka sendiri, sehingga berdampak pada pembatasan perolehan hak pada individu yang memperoleh stigma. Fenomena ini menjadi sebuah lingkaran setan yang telah sekian lama dilakukan upaya-upaya intervensi dalam rangka mengurangi pengaruhnya.

Stigma terhadap penderita kesehatan mental adalah masalah yang serius di Indonesia karena tingginya angka prevalensi masalah kesehatan mental. Menurut data Riskesdas, prevalensi gangguan jiwa berat, seperti skizofrenia mencapai sekitar 400.000 orang atau sebanyak 1,7\% pada tahun 2013 dan mengalami peningkatan proporsi yang cukup signifikan pada tahun 2018 jika menjadi 7\% (Kemenkes, 2018). Kegiatan promosi dan prevensi sebagai salah satu pendekatan psikososial, sangat dibutuhkan pada tiap tahapan proses pemulihan Orang Dengan Skizofrenia (ODS), sebagaimana tertuang dalam UU No. 18 Tahun 2014 tentang Kesehatan Jiwa, yang salah satunya memiliki tujuan untuk menghilangkan stigma, diskriminasi, pelanggaran hak asasi orang dengan gangguan jiwa (ODGJ) sebagai bagian dari masyarakat. Hal yang tampak sederhana tapi sangat bermakna dalam keberhasilan sebuah proses recovery adalah adanya stigma. Stigma mengakibatkan hambatan dalam pelayanan kesehatan gangguan jiwa secara maksimal, diantaranya mengakibatkan hambatan dalam deteksi dini, ketidaktepatan dalam diagnosis, pengabaian terhadap keluhan-keluhan secara fisik dan mental, yang berakibat pada tatalaksana yang tidak tepat dan kondisi akhir dari penyakit yang semakin buruk (Soebiantoro, J. 2017). Dalam hal ini penting adanya upaya intervensi yang dapat dilakukan untuk mengurangi stigma pada penderita gangguan jiwa khususnya Skizofrenia. Terdapat beberapa intervensi dan membutuhkan upaya bersama dari berbagai pihak dalam mengurangi stigma terhadap penderita skizofrenia.

\section{B. SKIZOFRENIA}

\section{Definisi}

Skizofrenia merupakan istilah yang berasal dari Bahasa Jerman yakni Schizo yang berarti perpecahan/ split dan Phrenos yang berarti Mind, dari istilah tersebut didapatkan definisi dari Skizofrenia adalah suatu kondisi perpecahan pikiran, perasaan, dan perilaku (Benhard R.S., 2007). Menurut Maramis (2009) Skizofrenia adalah suatu psikosa fungsional dengan gangguan utama pada proses pikir serta disharmonisasi antara proses pikir, afek atau emosi, kemauan dan psikomotor disertai distorsi kenyataaan terutama karena waham dan halusinasi, assosiasi terbagibagi sehingga muncul inkoherensi, afek dan emosi inadekuat, psikomotor menunjukkan penarikan diri, ambivalensi dan perilaku bizar. Skizofrenia dianggap sebagai sebuah penyakit otak yang paling membingungkan dengan manifestasi kondisi psikotik yang berat dan persisten disertai oleh variabel disfungsi kognitif dan gangguan psikososial yang mendalam dengan awitan terjadi pada waktu yang tidak biasa dalam kehidupan yakni dapat terjadi akhir masa remaja/awal masa dewasa dimana gejalanya sering tidak terdeteksi pada awal kehidupan, paling buruk selama tahun-tahun kehamilan, dan dapat membaik, sampai taraf tertentu, seiring dengan bertambahnya usia (Saddock, 2017).

\section{Etiologi}

Terdapat beberapa faktor dan teori yang mendasari terjadinya Skizofrenia (Kaplan and Sadock et al, 2015) diantaranya faktor genetik, faktor biokimia, neuropatologi, sirkuit saraf, teori psikososial dan psikoanalitik, dan dinamika keluarga tertentu.

\section{Terapi dan intervensi psikososial}

Pemberian farmakoterapi pada skizofrenia menggunakan obat-obatan antipsikotik yang memiliki berbagai macam sifat farmakologis yang bekerja pada reseptor postsinaptik dopamine di otak. Antipsikotik dapat dikategorikan ke dalam dua kelompok utama yakni antipsikotik konvensional (golongan yang lebih dulu), yang juga disebut antipsikotik penerasi pertama (APG I), antagonis reseptor dopamin, antipsikotik tipikal, dan obatobatan yang lebih baru, yang disebut antipsikotik generasi kedua (APG II) atau antagonis serotonin dopamine atau antipsikotik atipikal.

Penatalaksanaan secara holistik pada skizofrenia dapat memberikan hasil yang lebih optimal. Tiap oramg dengan skizofrenia memiliki kebutuhan psikososial masingmasing ODS tergantung kepada etiologi, perjalanan penyakit, dan prognosisnya. Penatalaksanaan psikososial lebih efektif pada saat berada pada fase perbaikan jika dibanding- 
kan pada fase akut, dan tergantung dengan tingkat keparahan gejala dan perjalanan penyakit yang membutuhkan dukungan dari banyak pihak (Benhard, 2007 dan Kusumawardhani, et al, 2015).

\section{Recovery}

Mental Health Recovery adalah suatu perjalanan atau transformasi penyembuhan dari seseorang yang mengalami masalah gangguan jiwa, menuju ke kehidupan yang bermakna di dalam komunitas sesuai pilihannya dengan cara mengupayakannya untuk mencapai seluruh potensinya. Recovery berarti keberhasilan seorang dengan skizofrenia untuk dapat menjalani kehidupannya secara bermanfaat dan produktif seperti kehidupannya sebelumnya, mampu bekerja, memperoleh pendidikan, dan berada di masyarakat serta berpartisipasi dalam lingkungan. Dalam mencapai recovery, hambatan yang masih membutuhkan perhatian yakni kuatnya stigma baik oleh diri pasien sendiri, oleh masyarakat, pemerintah, bahkan oleh tenaga kesehatan.

\section{STIGMA}

\section{Definisi Stigma}

The American Heritage Dictionary
mendefinisikan stigma sebagai sebuah aib atau ketidaksetujuan masyarakat terhadap sesuatu, seperti sebuah tindakan atau kondisi (The American Heritage Dictionary, 2012). Erving Goffman (1963) menyatakan stigma adalah suatu proses dinamis dari devaluasi yang mendiskreditkan seseorang secara mendalam yang mengurangi diri seseorang secara utuh, sehingga menjadi orang yang tercemar atau orang yang tidak utuh serta mendiskreditkan seorang individu dari individu lainnya dan berakibat seseorang diberlakukan secara berbeda dari yang lainnya, masalah ini jelas membuat orang atau kelompok yang mendapat stigma kehilangan kesempatan penting dalam hidupnya sehingga tidak mampu berkembang.

\section{Tipe Stigma}

Terdapat 6 tipe stigma menurut Van Brakel WH (2006) diantaranya Public stigma, Structural stigma, Selfstigma, Felt or perceived stigma, Experienced stigma, dan Label avoidance.

\section{Mekanisme dan Dimensi Stigma}

Mekanisme stigma dikaitkan dengan perspektif stigmatizer (yang memberikan stigma) dan yang terkait dengan perspektif mereka yang distigmatisasi (Fox, AB, et al, 2018). Berdasarkan perspektif yang memberi stigma yang terdapat tiga mekanisme yakni stereotip, prasangka, dan diskriminasi. Selanjutnya adalah bentuk mekanisme stigma yang dinilai dari perspektif individu yang mendapat stigma yakni Experienced stigma (pengalaman mendapat stigma), Anticipated stigma (stigma yang diantisipasi) dan Internalized stigma (stigma yang diinternalisasi).

Menurut Link dan Phelan (dalam Scheid \& Brown, 2010), ada beberapa bentuk (dimensi) stigma dalam masyarakat diantaranya labelling, stereotype, separation, dan diskriminasi. Dimensi-dimensi ini dapat hadir secara mandiri ataupun bersamaan untuk menciptakan stigma.

\section{Stigma dan dampaknya pada Skizofrenia}

Stereotip yang negatif tentang orang dengan skizofrenia, keyakinan diri, keluarga, dan masyarakat yang salah, serta kekhawatiran tentang diagnosis skizofrenia akan memperburuk kondisi penderita itu sendiri. Kuatnya stigma menyebabkan seseorang malu atau takut mencari pengobatan sehingga penyakitnya bertambah parah, kurang kepatuhan terhadap pengobatan (Emine et al, 2015). Dampak yang ditimbulkan oleh stigma lebih besar daripada dampak dari penyakit itu sendiri, seseorang tidak dapat mencapai tujuan hidup secara optimal, tidak dapat hidup mandiri, tidak bisa mendapatkan pekerjaan yang layak, kemampuan untuk bersosialisasi yang terhambat, interpersonal yang buruk, yang menyebabkan kualitas hidup buruk dan penurunan harga diri. Akibat stigma juga menyebabkan seseorang lebih rentan menjadi skizofrenia, akses layanan kesehatan yang buruk, keterlambatan dalam perilaku mencari pengobatan (Fox, AB, et al, 2017)., dan dapat memperberat psikopatologi yang ada.

\section{MENGURANGI STIGMA PADA SKIOFRENIA}

\section{Pengetahuan Dasar dalam Mengurangi Stigma}

Dalam upaya melakukan intervensi dalam mengurangi stigma pada penderita skizofrenia, terlebih dahulu diperlukan evaluasi permasalahan terkait stigma, eksplorasi dampak dan konsekuensi stigma, siapa yang terlibat dan proses recovery serta hasil yang diperoleh. Setelah langkah-langkah tersebut akan diperoleh daftar masalah serta keluhan terkait konsekuensi stigma dan selanjutnya dapat dilakukan pembagian tugas menurut letak permasalahannya, dan tergantung tingkat kesulitan dan ketersediaan dukungan atau sumber daya. Tiap program memiliki target yang berbeda, bersifat sementara ataupun bertahan lama, memiliki dasar dukungan yang kuat dari institusi, pemerintah atau organisasi, ataukah independen dan tidak memiliki banyak dukungan. Intervensi yang dilakukan dapat berupa penggabungan atau penyusunan ulang disesuaikan kondisi di In- 
donesia. Lebih baik jika mampu berinovasi dan menyusun strategi intervensi sendiri yang sesuai yang selanjutnya dilakukan evaluasi keberhasilan program.

\section{Jenis-jenis Strategi Intervensi dalam mengurangi Stigma}

Terdapat beberapa pihak yang dapat menjadi target intervensi (Thornicroft G. et al, 2015) diantaranya adalah masyarakat umum, orang dengan penyakit mental, siswa, dan staf layanan kesehatan, dan anggota keluarga ODS dengan menggunakan jenis intervensi yang sesuai.

\section{Narrative Enhancement Cognitive Therapy (NECT)}

Merupakan intervensi mandiri berbasis kelompok untuk mengurangi stigma diri, harga diri, identitas diri, berpedoman pada manual terstruktur, yang terdiri dari psikoedukasi, restrukturisasi kognitif, terapi naratif, memiliki total 20 sesi, masing-masing 60 menit. Dalam kelompok dengan dua fasilitator, dan anggota kelompok terdiri dari 6-8 peserta. Hasil studi menunjukkan pengurangan signifikan pada stigma diri, peningkatan harga diri, harapan, dan kualitas hidup (Roe et al., 2014).

\section{Intervensi Komprehensif Berbasis Komunitas}

Suatu studi uji coba intervensi komprehensif berbasis komunitas selama sembilan bulan (Jie Li et al., 2018) dengan topik terdiri dari Strategic Against Stigma and Discrimination (SASD), psikoedukasi, Social Skill Training (SST), dan Cognitive Behavioral Therapy (CBT). Intervensi komprehensif ini mungkin efektif untuk ODS, terutama untuk mengurangi diskriminasi, gejala klinis dan perbaikan fungsi sosial (Jie Li et al., 2018).

\section{Coming Out Proud (Pengungkapan)}

Intervensi ini menggunakan pedoman manual, berbasis kelompok, yang pertama kali diperkenalkan oleh Corrigan et al (2013), mengguankan pengungkapan diri sebagai metode utama, hidup secara terbuka, melatih ketrampilan komunikasi, dan asertif (Rüsch et al., 2014), terdiri dari tiga sesi, masing-masing 2 jam, seminggu sekali, dengan anggota kelompok 6-10 orang, dan dua fasilitator peers. Studi menunjukkan bahwa COP pertama menunjukkan pengurangan dalam stress akibat stigma, kerahasiaan, dan peningkatan manfaat yang dirasakan dalam pengungkapan yang berlanjut hingga follow up (Rüsch et al., 2014).

\section{Ending Self-Stigma (ESS)}

Intervensi kelompok untuk mengurangi stigma diri (self stigma), secara professional dalam bentuk program serta pelayanan kesehatan (Alicia L, et al, 2011), terdiri dari 9 sesi mingguan, 75-90 menit tiap sesi, 5-8 anggota dalam kelompok tertutup dan dipimpin oleh satu atau dua fasilitator. Prinsip yang digunakan dalam intervensi ini adalah menggabungkan teknik kognitif-perilaku, pendidikan yang relevan, latihan memperkuat kesadaran dan menggunakan kekuatan diri sendiri, serta mengubah perspektif seseorang tentang stigma.

\section{Anti-Stigma Photovoice Intervention}

Intervensi berbasis fotografi, mengambil gambar dengan kamera lalu menyertakan pernyataan pada gambar dengan kata-kata yang mengkomunikasikan pengalaman mereka dalam bentuk narasi, dilaksanakan dalam 10 sesi per minggu dalam kelompok, tiap sesi 90 menit, oleh instruktur atau fasilitator terlatih. Latihan photovoice disertai komponen psikoedukasi dan mengajarkan strategi "proaktif". Tujuan photovoice secara tidak langsung adalah mencoba berbicara dengan orang lain agar lebih memahami, dan menjadi alat agar orang lain dapat mengerti.

\section{Intervensi Media Massa}

Intervensi singkat berupa laporan di TV memiliki efek jangka panjang, pengurangan jarak sosial dan pembatasan pasien, dapat dipertahankan sampai 1 dan 3 bulan, dengan dampak yang berkelanjutan dalam mengurangi stig- ma dan diskriminasi (Nathaly et al, 2017). Suatu studi menunjukkan bahwa laporan berita dan posting media sosial yang positif cenderung mengurangi sikap stigmatisasi, dan sebaliknya (Anna M. Ross et al, 2018). Hal ini juga terjadi pada komentar di media online atau media sosial. Penggambaran media secara positif oleh orang-orang terkemuka akan berdampak penurunan aspek stigma.

\section{Intervensi Berbasis Kontak}

Program pendidikan berbasis kontak dinilai efektif mengurangi stigma, namun sejauh mana kontaknya tidak menentukan sejauh mana perubahan sikap peserta. Efektivitasnya bervariasi berdasarkan persepsi individu terhadap kualitas kontak. Kunci untuk efektivitas intervensi adalah kontak langsung, partisipasi dari kelompok sasaran, interaksi dengan orang yang memiliki pengalaman pribadi, dan diskusi terbuka dengan para peserta (Corrigan et al, 2014). Kontak dengan ODS diperlukan agar intervensi menjadi efektif (Thornicroft et al. 2016).

\section{E.HAMBATAN DAN TANTANGAN DALAM MENGURANGI STIGMA}

Keterbatasan atau tidak adanya kapasitas untuk penelitian, pendanaan penelitian, sedikit akses ke sumber 
daya, kurangnya dukungan secara teknis, atau kurang tersedianya sumber ilmu pengetahuan yang memadai, kesulitan menggabungkan komunitas anti-stigma dengan komunitas penelitian yang memiliki latar belakang budaya, cara pandang dan dasar ilmu pengetahuan yang berbeda menjadi hambatan dalam mengurangi stigma (Ferguson, 2005). masih sedikit studi program anti-stigma yang dilakukan untuk negara berkembang di mana justru sebagian besar ODS berada. Perlu pengaturan lintas budaya untuk memahami faktor sosial yang dapat memengaruhi sifat stigma dan kelayakan seerta keberhasilan intervensi anti-stigma (Mascayano et al. 2015). di negara berkembang program yang ada kurang berjalan baik, kurang dukungan finansial, bersifat simbolis, dan berdurasi pendek, tidak mencerminkan aktivitas yang berkelanjutan, serta tidak melibatkan ODS atau anggota keluarga (Beldie et al., 2012) dan masih memprioritaskan pada kondisi penyakit fisik daripada penyakit mental. Organisasi non-pemerintah juga sedikit sehingga tidak memiliki dukungan, pemberdayaan, dan advokasi seperti di negara maju. Kurangnya sumber daya manusia untuk melakukan intervensi sehingga perlu pengalihan tugas.

\section{F. RINGKASAN}

Dampak stigma pada skizofrenia merupakan hambatan besar untuk pemulihan, masalah dalam hubungan interpersonal, tidak dapat hidup mandiri, tidak bisa mendapatkan pekerjaan yang layak, sehingga kualitas hidupnya sangat buruk, hilangnya peluang, penurunan harga diri, hambatan kemampuan bersosialisai karena tidak diterima oleh masayarakat, hubungan yang kurang baik dengan anggota keluarga lainnya. Upaya intervensi dalam mengurangi stigma pada skizofrenia dimulai dengan mengevaluasi permasalahan terkait stigma yang menjadi perhatian utama di setiap daerah, sesuai letak permasalahannya dengan target yang berbeda. Intervensi dari berbagai negara memiliki keunggulan dan manfaat masingmasing, selanjutnya dapat dilakukan penggabungan ataupun penyusunan ulang agar dapat disesuaikan dengan kondisi yang ada di Indonesia, lebih baik jika mampu berinovasi dan menyusun strategi intervensi tersendiri, program dan intervensi antistigma yang dilakukan di negara maju juga membutuhkan validasi untuk dapat diterapkan di Indonesia.

Berbagai jenis strategi intervensi dalam mengurangi stigma diantaranya adalah NECT, Intervensi Komprehensif Berbasis Komunitas, Coming Out Proud (Pengungkapan), Ending Self-Stigma (ESS), Anti-Stigma Photovoice Intervention, Intervensi Media Massa, Intervensi Berbasis Kontak. Intervensi untuk mengurangi stigma juga dapat ditargetkan pada berbagai pihak diantaranya masyarakat umum, orang dengan penyakit mental, siswa, dan staf layanan kesehatan. Namun demikian, terdapat beberapa hambatan dan tantangan dalam mengurangi stigma yang perlu menjadi perhatian.

\section{DAFTAR PUSTAKA}

1. Baba, Y., Nemoto, T., Tsujino, N., Yamaguchi, T., Katagiri, N., Mizuno, M. (2017). Stigma toward Psychosis and Its Formulation Process: Prejudice and Discrimination against Early Stages of Schizophrenia. Comprehensive Psychiatry; 73:181-186. DOI: 10.1016/ j.comppsych.2016.11.005.

2. Beldie, A., den Boer, J.A., Brain, C., Constant, E., Figueira, M.L., Filipcic, I., Gillain, B., Jakovljevic, M., Jarema, M., Jelenova, D., Karamustafalioglu, O., Kores Plesnicar, B., Kovacsova, A., Latalova, K., Marksteiner, J., Palha, F., Pecenak, J., Prasko, J., Prelipceanu, D., Ringen, P.A., Sartorius, N., Seifritz, E., Svestka, J., Tyszkowska, M., Wancata, J. (2012). Fighting stigma of mental illness in midsize European countries. Social Psychiatry Psychiatric Epidemiology. 47 (Suppl 1):1-38. DOI: 10.1007/s00127-012-0491-z.

3. Benhard, RS. (2007). Skizofrenia dan Diagnosis Banding. Jakarta : Balai Penerbit Fakultas Kedokteran Indonesia.

4. Chatterjee, S., Naik, S., John, S., Dabholkar, H., Balaji, M., Koschorke, M., Varghese, M., Thara, R., Weiss, H.A., Williams, P., McCrone, P., Patel, V., Thornicroft, (2014). Effectiveness of a Community-Based Intervention for People with Schizophrenia and Their Caregivers in India (COPSI): a Randomised Controlled Trial. Lancet 383, 1385-1394. DOI: 10.1016/S0140-6736 (13)62629-X

5. Cooper, A.E., Corrigan, P.W., \& Watson, A.C. (2003). Mental Illness Stigma and Care Seeking. Journal of Nervous and Mental Disease. 191 (5). DOI: 10.1097/01.NMD.0000066157.47101.22

6. Corrigan, P.W., Michaels, P.J., Vega, E., Gause, M., Larson, J., Krzyzanowski, R., Botcheva, L. (2014). Key Ingredients to Contact-based Stigma Change: A crossValidation. Psychiatric Rehabilitation Journal, 37 (1) 62 -64. DOI: 10.1037/prj0000038

7. Corrigan, PW, Kosyluk, KA, \& Rüsch, N. (2013). Reducing Self-stigma by Coming Out Proud. American Journal of Public Health, 103, 794- 800. DOI: 10.2105/ AJPH.2012.301037.

8. Fox, A.B., Earnshaw, V.A., Taverna, E.C., Vogt, D. (2018). Conceptualizing and Measuring Mental Illness 
Stigma: The Mental Illness Stigma Framework and Critical Review of Measures. Stigma and Health (4): 348-376. DOI: $10.1037 /$ sah0000104.

9. Goffman, Erving. (1963). Stigma: Notes on the Management of Spoiled Identity. Englewood Cliffs, NJ: Prentice Hall.

10. Goffman, Erving. (1959). Presentation of Self in Everyday Life. New York: Doble day Company.

11. Hansson L, Lexén A, Holmén J. (2017). The Effectiveness of Narrative Enhancement and Cognitive Therapy: a Randomized Controlled Study of a Self-stigma Intervention. Social Psychiatry and Psychiatric Epidemiology 52 (11):1415-1423. doi: 10.1007/s00127-017-1385-x.

12. Hawari, D. (2001). Pendekatan Holistik Pada Gangguan Jiwa Skizofrenia. Jakarta Indonesia: Gaya Baru

13. Heatherton, TF, Kleck, Hebl, dan Hull. (2003). The Social Psychology of Stigma. New York: The Guilford Press.

14. Kementrian Kesehatan Republik Indonesia. (2018). Potret Sehat Indonesia dari Riskesdas 2018. http://www.depkes.go.id/article/view/18110200003/potretsehat-indonesia-dari-riskesdas-2018.html.

15. Kusumawardhani, AAAA, Dharmono, S., Amir, N., Diatri, H, Malik, K. (2015). From Curing to Caring Achieving Patient's Recovery. Seksi Skizofrenia Perhimpunan Dokter Spesialis Kedokteran Jiwa Indonesia.

16. Maramis, WF, dan Maramis, AA. (2009). Catatan Ilmu Kedokteran Jiwa. Surabaya : Airlangga University Press.

17. Pattyn, E., Verhaeghe, M., Sercu, C., Bracke, P. (2014). Public Stigma and Self-stigma: Differential Association with Attitudes toward Formal and Informal Help Seeking. Psychiatric Services; 65(2):232-8. DOI: 10.1176/ appi.ps. 201200561

18. Roe, D., Hasson-Ohayon, I., Mashiach-Eizenberg, M., Derhy, O., Lysaker, P.H., Yanos, P.T. (2014). Narrative Enhancement and Cognitive Therapy (NECT) Effectiveness: A Quasi-Experimental Study. Journal of Clinical Psychology, 70, 303-312. DOI: 10.1002/jclp.22050

19. Rüsch, N., Abbruzzese, E., Hagedorn, E., Hartenhauer, D., Kaufmann, I., Curschellas, J., Ventling, S., Zuaboni, G., Bridler, R., Olschewski, M., Kawohl, W., Rössler, W., Kleim, B., Corrigan, P.W. (2014). Efficacy of Coming Out Proud to Reduce Stigma's Impact among People with Mental Illness: Pilot Randomised Controlled Trial. The British Journal of Psychiatry, 204, 391-397. DOI: 10.1192/bjp.bp.113.135772.
20. Russinova, Z., Rogers, E.S., Gagne, C., Bloch, P., Drake, K.M., Mueser, K.T. (2014). A Randomized Controlled Trial of a Peer-run Antistigma Photovoice Intervention. Psychiatric Services, 65, 242-246. DOI: 10.1176/ appi.ps. 201200572

21. Sadock, Benjamin J., Virginia A. Sadock, Pedro Ruiz. (2017). Kaplan \& Sadock's Comprehensive Textbook of Psychiatry, 10th edition, Wolters Kluwer, Philadelphia, USA, bab 12 Schizophrenia Spectrum and Other Psychotic Disorders.

22. Sadock, Benjamin J., Virginia A. Sadock, Pedro Ruiz. (2015). Kaplan \& Sadock's Synopsis of Psychiatry Behavioral Sciencel Clinical Psychiatry, 11th edition, Wolters Kluwer, Philadelphia, USA, bab 7 Schizophrenia Spectrum and Other Psychotic Disorders.

23. Scheid, T.L., \& Brown, T.N. (2010). A Handbook For Study Of Mental Health Social Contexts. New York: Cambridge University Press.

24. Singh, A., Mattoo, S.K., Grover, S. (2016). Stigma and its correlates among caregivers of schizophrenia: A study from North India. Psychiatry Research 30; 241:302-8. DOI: 10.1016/j.psychres.2016.04.108.

25. Soebiantoro, J. (2017). Pengaruh Edukasi Kesehatan Mental Intensif Terhadap Stigma Pada Pengguna Layanan Kesehatan Mental. Jurnal Psikologi dan Kesehatan Mental VOL 2, NO 1. http:// dx.doi.org/10.20473/jpkm.V2I12017.1-21

26. Stahl, S.M. (2013). Stahl's Essensial Psychopharmachology Neuroscientific Basis and Practical Application, New York : Cambridge University Press.

27. Stuart, H. (2016). Reducing The Stigma of Mental Illness. Centre for Health Services and Policy Research, Queen's University, Kingston, Ontario, Canada Global Mental Health 3, e17, page 1 of 14. doi:10.1017/gmh.2016.11

28. Thornicroft, G., Mehta, N., Clement, S., Marcus, E., Stona, A.C., Bezborodovs, N., Evans Lacko, S., Palacious, J., Dochery, M., Barley, E., Rose, D., Koschorke, M.., Shidhaye, R., Henderson, C. (2015). Evidence for effective interventions to reduce mental health-related stigma and discrimination in the medium and long term: systematic review. British Journal of Psychiatry: The Journal of Mental Science, 207 (5): 377-84. DOI: 10.1192/bjp.bp.114.151944.

29. Warner, R. (2009). Recovery from schizophrenia and the recovery model. Current Opinion in Psychiatry 22 (4):374-80. DOI: 10.1097/YCO.0b013e32832c920b.

30. Yanos P.T., Roe, D., Lysaker, P.H. (2011). Narrative enhancement and cognitive therapy: a new group-based 
treatment for internalized stigma among persons with severe mental illness. International Journal Group Psychotherapy; 61 (4): 576-595. DOI: 10.1521/ ijgp.2011.61.4.576.

31. Yanos, P.T., Lucksted, A., Drapalski, A.L., Roe, D., Lysaker, P. (2015). Interventions Targeting Mental Health Self-Stigma: A Review and Comparison. Psychiatric Rehabilitation Journal Vol. 38, No. 2, 171178. DOI: 10.1037/prj0000100. 